\title{
Double Inferior Vena Cava Detected by CT Venography and Confirmed by Magnetic Resonance Venography: Embryogenesis and Literature Review
}

\author{
Doble Vena Cava Inferior Detectada a través de Venografía por Tomografía Computada y Confirmada con \\ Venografía por Resonancia Magnética: Embriogénesis y Revisión de la Literatura
}

Maher T. Hadidi*; Darwish H. Badran*; Jamal Abu Ghaida**; Amjad T. shatarat; Azmy M. Al-Hadidy ${ }^{* * *} \&$ Emad Tarawneh $^{* * *}$

HADIDI, M. T. ; BADRAN, D. H. ; GHAIDA, J. A.; SHATARAT, A. T.; AL-HADIDY, A. M. \& TARAWNEH, E. Double inferior vena cava detected by $\mathrm{CT}$ venography and confirmed by magnetic resonance venography: Embryogenesis and literature review. Int. $J$. Morphol., 34(2):1087-1091, 2016.

SUMMARY: A hospital based prospective study was conducted from July 2001 to July 2015 at the Department of Radiology, Jordan University Hospital, Amman, Jordan. During that period, five cases of double inferior vena cava (DIVC) were discovered among a cohort of 7722 patients ( 3861 men and 3861 women, $49.5 \pm 16.9$ years, range 16-78 years). Cases were diagnosed by contrast-enhanced Spiral CT venography (CTV) and confirmed by turbo three-dimensional (3D) time-of-flight contrast-enhanced MR venography. The majority of patients $3166(41 \%)$ were referred for staging and follow-up of malignancy, postoperative complications 1777 (23\%), nonspecific abdominal pain 1467 (19\%), preoperative assessment $849(11 \%)$ and trauma $463(6 \%)$. Magnetic resonance venography showed higher sensitivity, diagnostic accuracy and noninvasive modality for assessment of IVC map. MRV is a more useful, noninvasive modality for assessment of IVC map. DIVC is a common anomaly, its incidence in our study found to be $0.064 \%$. The incidence, literature review, embryogenesis, and importance of this anomaly are discussed. In addition, sample figures of relevant cases are provided.

KEY WORDS: Magnetic resonance angiogram; Inferior vena cava; Congenital anomalies.

\section{INTRODUCTION}

Congenital anomalies of the inferior vena cava (IVC) vary, reflecting the developmental intricacy of these vessels (Kumar et al., 2008). Double IVC (DIVC) has 0.2-3\% prevalence (Phillips 1969). Double IVC has been detected accidentally in autopsy, imaging techniques (Rettori et al., 1989; Saito et al., 1995) and during clinical intervention (Hsiao et al., 1997).

The embryonogenesis and anomalies of the IVC have been described in numerous reports (Phillips, Bass et al., 2000; Minniti et al., 2002). During the fifth to the eighth week of embryonic period, the IVC develops as a composite structure via chronological events of formation, regression, anastomosis and substitution of three symmetrical sequential pairs of veins, the posterior cardinal, subcardinal and supracardinal (Artico et al., 2004). The right IVC typically reassembled through four caudocranial embryologic segments: subrenal, renal, suprarenal and hepatic. The posterior cardinal veins persist as the caudal portion of the subrenal segment that gives the common iliac veins and the bifurcation. The supracardinal vein gives the cranial portion of the subrenal segment. The right subcardinal-supracardinal anastomosis gives the renal segment. The subcardinal vein provides the suprarenal segment. The cardiohepatic canal gives the hepatic segment (Artico et al.). In view of the fact that, each pair of veins is identical in origin but not in fate, the unusual development of these venous systems, for unknown reason/s, causes variations of the IVC and alter the venous map of the abdomen (Artico et al.). Its pathogenesis is generally attributed to the failure of regression of the left supracardinal vein (Mao et al., 2015).

\footnotetext{
* Department of Anatomy and Histology, School of Medicine, The University of Jordan, Amman, Jordan.

** Department of Anatomy, Faculty of Medicine, Jordan University of Science and Technology, Irbio, Jordan.

**** Department of Radiology and Nuclear Medicine, School of Medicine, The University of Jordan, Amman, Jordan.
} 
The clinical significance of DIVC is essentially an incidental finding that commonly recognized in asymptomatic patients. Cossu et al. (2000) estimated its incidence to be $0.2-3 \%$ in autopsy, $0.2-6 \%$ intraoperatively and 0.3-1 \% in CT reports (Mayo et al., 1983). The advancement in imaging techniques has improved the detection of congenital variations of the IVC and encountered more in asymptomatic patients (Bass et al.). Their radiological diagnoses usually made during patient evaluation or follow up by various imaging techniques, for other anomalies or diseases. CT and MRV are non-invasive, effective techniques for diagnosing diseases of the retroperitoneal space (Tatar et al., 2005; Spritzer, 2009). Since the development of CT, congenital anomalies of the IVC and its tributaries encountered more frequently in asymptomatic patients (Schultz et al., 1984). MRV is the technique of choice for investigating this anomaly, and provides images that are diagnostic and easy to interpret.

We report five cases of DIVC out of 7722 patients diagnosed by contrast-enhanced Spiral CT venography (CTV) and confirmed by Turbo three-dimensional (3D) timeof-flight contrast-enhanced MR venography (MRV) (3D contrast-enhanced MRV). To our knowledge, these are the first five cases of DIVC reported in Jordan. The incidence, embryology, literature review and importance of this anomaly are discussed.

\section{MATERIAL AND METHOD}

A hospital based prospective study was conducted between July 2001 to July 2015 at the Department of Radiology, Jordan University Hospital, Amman, Jordan. Five cases of DIVC were discovered among a cohort of 7722 patients (3861 men and 3861 women, $49.5 \pm 16.9$ years, range 16-78 years) were selected from those referred for abdominal angiography, routine/ enhanced abdominal CT for advanced evaluation of possible abdominal problems. Those showed retroperitoneal vascular suspicion rechecked by contrast-enhanced Spiral CTV and confirmed by coronal Turbo three-dimensional (3D) time-of-flight contrastenhanced MRV (3D CE MRV). The majority of patients 3166 $(41 \%)$ were referred for staging and follow-up of malignancy, postoperative complications 1777 (23\%), nonspecific abdominal pain 1467 (19\%), preoperative assessment $849(11 \%)$ and trauma $463(6 \%)$. All patients provided informed consents. Our Institutional review Board approved this study.

Technique. Contrast-enhanced Spiral CTV: All suspected patients underwent Contrast-enhanced Spiral CTV
(Somatom plus 4, Siemens, Erlangen, Germany) to detect and asses IVC anomalies. Eight mm axial images of the chest, abdomen and pelvis obtained after oral contrast (E-Z-Cat $\left.{ }^{\circledR}\right)$ and $100-120 \mathrm{ml}$ of intravenous Ultravist contrast $300 \mathrm{mg} /$ $\mathrm{ml}$, velocity $1.5 \mathrm{ml} / \mathrm{s}$ (Schering, Allemagne, Germany). Each patient scanned 15-17 seconds for three runs with instant image source obtained on 150X256 matrix (Fig. 1). The coronal CT scan reconstruction of $32-40$ portions in every patient was reconstructed to show full image of the IVC. More anterior cuts in imaging process obtained to the same regions and settings to show final destination of the left IVC and its relation to the aorta (Fig. 2).

Three-dimensional contrast-enhanced magnetic resonance venography (3D CE MRV): Suspected patients underwent coronal AP scanning in supine position for the IVC by Turbo (3D CE MRV) time-of-flight (TOF). Moreover, fast low angle shot (FLASH) on a magnetic vision plus scanner using superconductive 1.5-Tesla magnet system (Siemens, Erlangen, Germany). Images were captured in the coronal plane while patients in supine position and AP scanning. Field of view (FOV) set on 400-450 mm, slab thickness $96-120 \mathrm{~mm}$, effective thickness $3 \mathrm{~mm}$ and flip angle 300. Patients received nondiluted gadolinium chelate contrast agent (Magnevist, Schering, Berlin, Germany) injected into the left great saphenous vein at a dosage of 2 $\mathrm{mmol} / \mathrm{Kg}$ in every run. Coronal T1-weighted single spin echo images performed with a repetition time (TR) 4 millisecond, echo time (TE) 1.6 millisecond of the thigh and pelviabdominal regions showing their veins for one rapid acquisition.

\section{RESULTS}

Five cases of double IVCs were detected among the cohort of 7722 patients. The contrast-enhanced Spiral CTV images revealed double IVC on both sides of the abdominal aorta in five patients (Fig. 1). The coronal CT scan reconstruction showed that the left IVC ascends along the left side of aorta to the left renal hila (Fig. 2). There, the left IVC (LIVC) received the left renal vein and then crossed obliquely anterior to the aorta just below the origin of the superior mesenteric artery and joined the right IVC vein (RIVC) (Fig. 2). The RIVC being normal ascends to the right renal hila after receiving the LIVC (Fig. 2). The remainder course of the RIVCs was normal. The mean diameter of the LIVC was $17 \pm \mathrm{mm}$, RIVC $24 \pm \mathrm{mm}$, and preaortic trunk $33 \pm \mathrm{mm}$ (Fig. 2). The IVC map in our five cases, demonstrated complete bilateral duplication of two asymmetrical IVCs, smaller LIVC, and larger RIVC and dominant is the preaortic trunk (Fig. 2). 
The 3D CE MRV demonstrated absence of common iliac anastomosis and each IVC had its own internal and external iliac veins (Fig. 3). The left common iliac vein assembled normally at L5 level then ascended on behalf of the LIVC along the left side of the aorta until the hilum of the left kidney. There, the left renal veins terminated into the left IVC (Fig. 3).

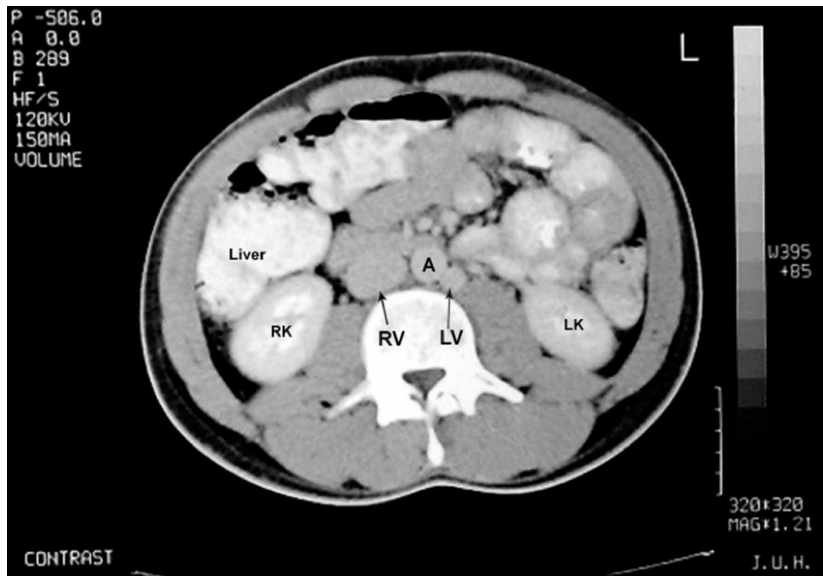

Fig. 1. Axial CT scan of the abdomen. $A=A o r t a, R V=$ Right Vena cava, $L V=$ Left vena cava, RK= Right kidney, LK= left kidney.

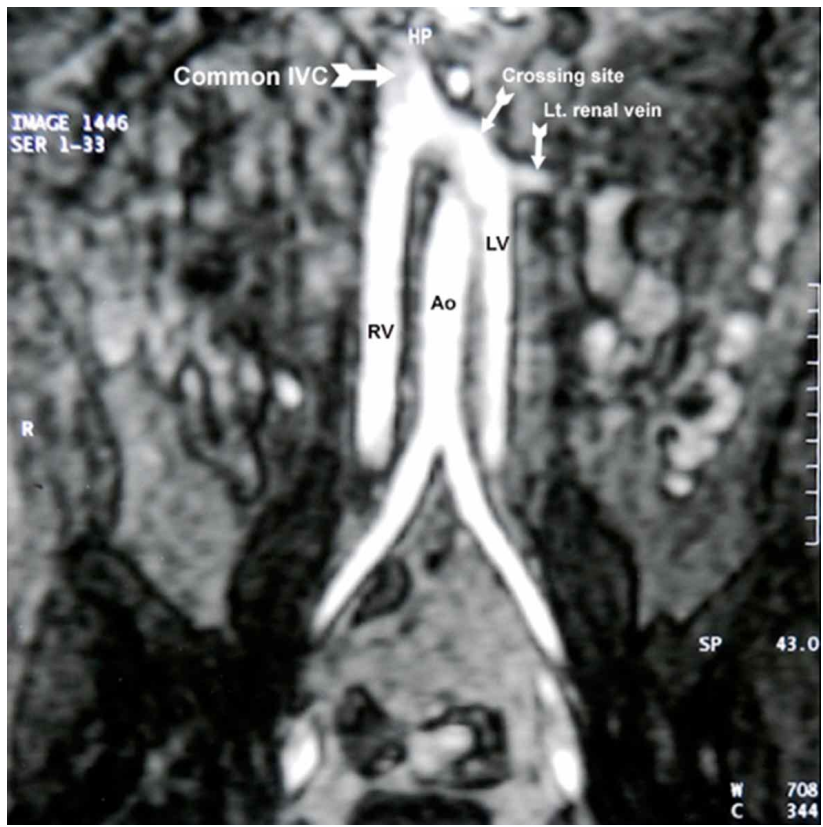

Fig. 2. Coronal CT scan reconstruction of the abdomen showing communication between the right and left inferior vena cava. Ao= Aorta, RV= Right Vena cava, LV= Left vena cava.

\section{DISCUSSION}

Double IVC is a relatively infrequent vascular anomaly. Contrary to expectation, modern surgical

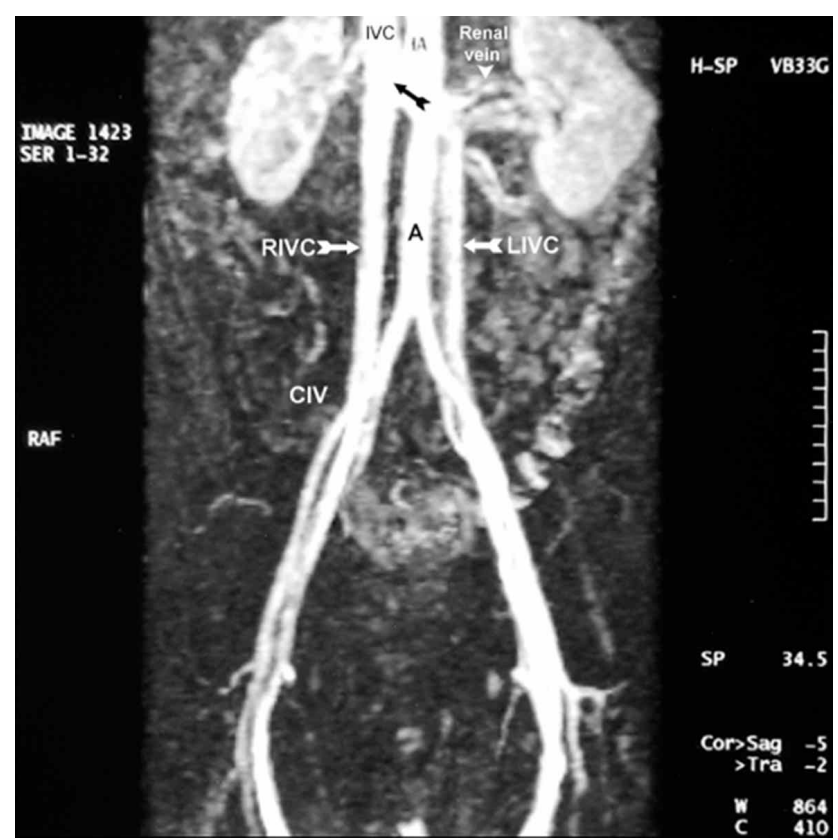

Fig. 3. Magnetic resonance venogram demonstrating the absence of common iliac anastomosis to form the left inferior vena cava (LIVC) and the termination of the left renal vein in the left inferior vena cava. $\mathrm{A}=\mathrm{Aorta}, \mathrm{CIV}=$ common iliac vein, $\mathrm{RIVC}=$ Right inferior vena cava.

techniques do not seem to have increased its reported incidence. Indeed, frequency by modern imaging techniques using $\mathrm{CT}$ and/or MRA are comparable to those found in the dissecting room or at surgery e.g. $0.62 \%$ in 161 cadavers (Ongoiba et al., 2006), $0.64 \%$ in 342 nephrectomies (Baptista-Silva et al., 1997), $1.03 \%$ upon CT (Ueda et al., 1983). Our five cases are the first diagnosed from a pool of 7722 patients evaluated by CT and MRV in Jordan, with frequency rate $0.002 \%$. This rate is different to reported prevalence of $0.08 \%$ and $0.02 \%$, similarly obtained by CT, MRV or both. The DIVC is the variation most commonly found during routine clinical checks (Senecail et al., 1987). It can be associated with other venous anomalies such as suprarenal and gonadal veins (Surucu et al., 2001). Diagnosis of DIVC is possible bearing in mind the relative position of the gonadal vein and the IVC, the continuity from the common iliac vein to the IVC and the degree of enhancement by contrast from the lower extremity (Artico et al.). Closure of one of the two IVC during surgery may be dangerous in the absence of iliac anastomosis (Dumas et al., 1986). In hypertensive patients with DIVC, it is important to employ imaging techniques as CT scanning, to avoid dilution of rennin sampling from the left renal vein (Artico et al.).

The discrepancy of incidences could be explained on the basis that cases of DIVC are still liable to be overlooked when using imaging techniques, as compared 
with dissection or at surgery. It should be kept in mind that DIVC can be confused upon imaging with normal structures including inferior mesenteric artery, gonadal vessels and the ureter, especially when one of the IVCs is small in diameter.

In addition, a variety of abnormal conditions can cause confusion, making the correct diagnosis more difficult as para-aortic lymphadenopathy, retroperitoneal tumors, hydroureter, venous thrombosis and varicocele. Nevertheless, cross sectional imaging techniques (CT, MRI and MRA) can be regarded as reliable and less invasive methods for the diagnosis of DIVC as well as other vascular anomalies. 3D CE MRV was reported to be a sensitive and correct technique for detecting any pathology of the IVC (Lin et al., 2005). Computer tomography also has been used widely and successfully. Ultrasound, often regarded as a valuable supplement to $\mathrm{CT}$ and should be adopted only with caution, since anomalies of the IVC have been reported as being missed using this technique.

The position and actuality of the IVC must be checked in every assessment for the retroperitoneal space. Though frequently asymptomatic, radiologists must identify congenital anomalies of the IVC properly. This avoids misinterpretation of unexpected findings and provides an accurate plan for surgical and interventional procedures when anomalous venous map exists.

MAHER T. HADIDI; DARWISH H. BADRAN; JAMAL ABU GHAIDA; AMJAD T. SHATARAT; AZMY M. AL-HADIDY \& EMAD TARAWNEH. Doble Vena Cava Inferior Detectada a través de Venografía por Tomografía Computada y Confirmada con Venografía por Resonancia Magnética: Embriogénesis y Revisión de la Literatura. Int. J. Morphol., 34(3):1087-1091, 2016.

RESUMEN: En el Departamento de Radiología del Hospital de la Universidad de Jordania, Amman, Jordania, se llevó a cabo un estudio prospectivo entre el mes de julio de 2001 al mes de julio del 2015 . Durante ese período se descubrieron cinco casos de vena cava inferior doble (VCID) en una cohorte de 7722 pacientes (3861 hombres y mujeres 3861 , de 49,5 $\pm 16,9$ años, con un rango de edad de 16-78 años). Los casos fueron diagnosticados por medio de venografía por tomografía computada espiral con contraste (TCV) y confirmados por medio de venografía por estudio tridimensional turbo. La mayoría de los pacientes (3166, $41 \%)$ fueron remitidos para estadificación y seguimiento de tumores malignos. Se presentaron complicaciones postoperatorias en 1777 pacientes (23\%), dolor abdominal no especificado en 1467 (19\%), evaluación preoperatoria en 849 (11\%) y traumatismo en 463 pacientes (6\%). La venografía por resonancia magnética (RMV) mostró una mayor sensibilidad, precisión diagnóstica, y resultando no invasiva para la evaluación de la vena cava inferior (VCI). RMV es una modalidad más útil, no invasiva para la evaluación de la VCI. VCID es una anomalía frecuente, encontrándose en nuestro estudio una incidencia de 0,064 \%. Además se realizó una revisión de la literatura, la embriogénesis, y la importancia de esta anomalía. También, se proporcionaron cifras de muestras de los casos relevantes.

PALABRAS CLAVE: Angiografía por resonancia magnética; Vena cava inferior; Anomalías congénitas.

\section{REFERENCES}

Artico, M.; Lorenzini, D.; Mancini, P.; Gobbi, P.; Carloia, S. \& David, V. Radiological evidence of anatomical variation of the inferior vena cava: report of two cases. Surg. Radiol. Anat., 26(2):153-6, 2004.

Baptista-Silva, J. C.; Veríssimo, M. J.; Castro, M. J.; Câmara, A. L. \& Pestana, J. O. Anatomical study of the renal veins observed during 342 living-donor nephrectomies. São Paulo Med. J., 115(3):1456-9, 1997.

Bass, J. E.; Redwine, M. D.; Kramer, L. A.; Huynh, P. T. \& Harris, J. H. Jr. Spectrum of congenital anomalies of the inferior vena cava: cross-sectional imaging findings. Radiographics, 20(3):639-52, 2000.

Cossu, M. L.; Ruggiu, M.; Fais, E.; Spartà, C.; Dettori, G. \& Noya, G. Congenital anomalies of the inferior vena cava. Minerva Chir., 55(10):703-8, 2000.
Hsiao, T. H.; Chang, H. P. \& Liu, K. M. A case of double inferior venae cavae. Kaohsiung J. Med. Sci., 13(7):453-6, 1997.

Kumar, S.; Panigrahy, B.; Ravimohan, S. M.; Pandya, S.; Mandal, A. K. \& Singh, S. K. Rare case of renal cell carcinoma with double inferior vena cava with venous thrombosis. Urology, 72(2):461.e7-10, 2008.

Lin, J.; Zhou, K. R.; Chen, Z. W.; Wang, J. H.; Yan, Z. P. \& Wang, Y. X. Vena cava 3D contrast-enhanced MR venography: a pictorial review. Cardiovasc. Intervent. Radiol., 28(6):795-805, 2005.

Mao, Y. Q.; Zhu, S. X. \& Zhang, W. The iatrogenic injury of double vena cava due to misdiagnosis during the radical nephroureterectomy and cystectomy. World J. Surg. Oncol., 13:41, 2015. 
HADIDI, M. T. ; BADRAN, D. H. ; GHAIDA, J. A.; SHATARAT, A. T.; AL-HADIDY, A. M. \& TARAWNEH, E. Double inferior vena cava detected by CT venography and confirmed by magnetic resonance venography: Embryogenesis and literature review. Int. J. Morphol., 34(2):1087-1091, 2016.

Mayo, J.; Gray, R.; St. Louis, E.; Grosman, H.; McLoughlin, M. \& Wise, D. Anomalies of the inferior vena cava. A. J. R. Am. J. Roentgenol., 140(2):339-45, 1983.

Minniti, S.; Visentini, S. \& Procacci, C. Congenital anomalies of the venae cavae: embryological origin, imaging features and report of three new variants. Eur. Radiol., 12(8):2040-55, 2002.

Ongoïba, N.; Destrieux, C.; Desme, J. \& Koumare, A. K. [Abnormal features of the sub renal portion of the inferior vena cava Morphologie, 90(291):171-4, 2006.

Phillips, E. Embryology, Normal Anatomy, and Anomalies. In: Ferris, E. J.; Hipona, F. A.; Kahn, P. C.; Phillips, E. \& Shapiro, J. H. (Eds.). Venography of the Inferior Vena Cava and its Branches. Baltimore, Williams \& Wilkins, 1969. pp.1-32.

Rettori, R.; Larroque, P. \& Benzimra, J. C. Clinical and paraclinical identification by various imaging technics of congenital anomalies of the inferior vena cava (apropos of 4 cases). J. Mal. Vasc., 14(3):191-201, 1989.

Saito, H.; Sano, N.; Kaneda, I.; Arakawa, M.; Ishida, S.; Takahashi, S. \& Sakamoto, K. Multisegmental anomaly of the inferior vena cava with thrombosis of the left inferior vena cava. Cardiovasc. Intervent. Radiol., 18(6):410-3, 1995.

Schultz, C. L.; Morrison, S. \& Bryan, P. J. Azygos continuation of the inferior vena cava: demonstration by NMR imaging. $J$. Comput. Assist. Tomogr., 8(4):774-6, 1984.

Spritzer, C. E. Progress in MR imaging of the venous system. Perspect. Vasc. Surg. Endovasc. Ther., 21(2):105-16, 2009.

Tatar, I.; Tore, H. G.; Celik, H. H. \& Karcaaltincaba, M. Magnetic resonance venography of double inferior vena cava. Saudi Med. J., 26(1):101-3, 2005.

Ueda, J.; Hara, K.; Kobayashi, Y.; Ohue, S. \& Uchida, H. Anomaly of the inferior vena cava observed by CT. Comput. Radiol., 7(3):145-54, 1983.
Correspondence to:

Darwish H. Badran

Professor of Anatomical Sciences

School of Medicine

University of Jordan

Amman, 11942

JORDAN

Tel : 00-962-6-5355000 Ext. 23401

Fax: 00-962-6-5300820

Email: dhbadran@ju.edu.jo

Received: 09-05-2016

Accepted: 22-06-2016 